Organized in three parts this paper describes, in the first, historical and social circumstances which preceded the emergence of visual culture emphasizing divergences between the notions of fine arts and handcraft. In the second it characterizes visual culture its projects and purposes as a field of knowledge and pedagogic practice. The last part focuses the importance of critical interpretation and how it constructs its way within visual culture education.

Keywords: visual culture, pedagogic practice, critical interpretation. 


\section{Porque e como falamos da cultura visual?}

Raimundo MARTINS

Organizado em três partes, este artigo descreve, na primeira, circunstâncias históricas e sociais que precederam a emergência da cultura visual destacando as divergências entre as noções de belas artes e artesanato. Na segunda, caracteriza a cultura visual e seus projetos e propósito como campo de conhecimento e prática pedagógica. Na última, foca a importância da interpretação crítica e a forma como ela se insere na educação da cultura visual.

Palavras-chave: cultura visual, prática pedagógica, interpretação crítica. 
Uma das mudanças fundamentais que afetou as práticas artísticas nas três últimas décadas foi a perda do estatuto ontológico da arte e, em decorrência, a dissolução das especificidades e traços essenciais que a caracterizavam. Idéias como "autonomia", "originalidade" e "autenticidade", outrora conceitos que distinguiam a obra de arte, foram gradativamente distanciando obra e fazer artístico dos processos e práticas do cotidiano. A idéia de autonomia da 'obra de arte autêntica' (ADORNO, 1970), preceito que privilegia a análise do objeto de arte em detrimento da experiência estética, contribuiu para o isolamento da arte em relação ao mundo material e à práxis da vida tendo como implicação uma esterilização do potencial da arte como crítica social (SHUSTERMAN, 1998).

O que está em disputa nessa mudança e nessa discussão é a distinção humanística entre história da arte e história do design institucionalizada nos departamentos universitários dos países de língua inglesa. Esta distinção continua, de certa maneira, colada ao etos das instituições universitárias e, por extensão, de associações profissionais e de pesquisadores. É uma disputa silenciosa, parte de um jogo estratégico que, de quando em vez, aflora em encontros de pesquisa, em reuniões de departamento, mas, principalmente, em discussões sobre currículo. Ainda persiste, embora de forma velada, a velha distinção kantiana entre "belas artes", ou "fine arts", e artesanato, distinção que se estabeleceu nas instituições do sistema moderno das belas artes e que ainda se faz contemporânea através de uma dualidade igualmente excludente, "arte erudita" e "arte popular".

\section{Perambulando por caminhos que levam à cultura visual}

O sistema moderno das belas artes se estabeleceu na primeira metade do século XIX quando o termo "arte" passou a designar não apenas uma categoria, mas, também, um espaço autônomo que incluía obras e interpretações, valores e instituições. Nesse novo contexto de autonomia, as obras de arte passaram a ser interpretadas a partir do conceito de "forma", 
implantado num vazio cultural, e, além disso, seus enunciados fundamentados na subordinação ao objeto arte (TRAFí, 2003). O processo de cooptação do público para aceitar e incorporar uma atitude silenciosa, de atenção e reverência à obra de arte exigiu tempo e esforço. De forma indireta e gradual, esse comportamento e atitude contribuíram para instituir e, posteriormente, institucionalizar o "discurso do artista como fonte original da produção de significado e a obra como seu receptáculo" (TRAFí, 2003, p. 267).

Paralelamente a este status da arte as teorias formalistas ganharam força entre críticos literários, críticos de arte e estetas. A divisão entre arte e artesanato também foi usada com interesses específicos, como por exemplo, para apropriação da arte de outras culturas. Assim, esse discurso formalista da arte sedimentou diferenças que passaram a distinguir a 'verdadeira' arte como "um ato de expressão imaginativa que requer compreensão interpretativa" (SHINER, 2004, p. 356).

A arte passou a ser tratada como uma essência metafísica reconhecida pelos seus méritos técnicos, mas, principalmente, pelo seu status filosófico, como pretendiam os filósofos idealistas. Dessa maneira, obras de arte, criação e fruto da inspiração, passaram a ser

Reverencialmente admiradas de um modo estético, por si mesmas, em um estado mental e de comportamento firmemente inculcado no público de concertos e nos visitantes de museus. A zona sombria da elevação da arte no século XIX foi o subseqüente retrocesso dos ofícios e das artes populares, a redução de muitos artesãos a meros operários industriais e a crescente separação entre os públicos das belas artes e das artes populares. No final do século XIX, a grande divisão do século XVIII havia se convertido num abismo (SHINER, 2004, p. 308).

Por aproximadamente cento e cinqüenta anos a divisão entre arte e artesanato se manteve estável e vigente, mas as tentativas de transcender a separação entre arte e vida, caracterizada por Shiner como um abismo, aos poucos ganharam força e intensidade. Os dadaístas (1916) realizaram vários ataques ao sistema das belas artes. De maneira irônica e sarcástica eles buscavam, publicamente, uma maneira de enfraquecer o 
sistema e suas instituições tentando uma reaproximação entre arte e vida. Os construtivistas russos encetaram campanhas e denúncias ainda mais demolidoras e as sustentaram através do seu próprio trabalho para as indústrias e para o Estado.

Na primeira metade do século XX foram muitos os esforços no sentido de reconciliar arte e vida. Como exemplo, podemos citar a Oficina de Investigação Surrealista, na Paris dos anos 20, os filmes sobre realismo social, as novelas e pinturas dos anos 30, os happenings realizados em Nova York, nos anos 50, e o movimento Fluxus dos anos 60 (SHINER, 2004; KAPROW, 1993).

É importante reconhecer que, apesar dessas muitas tentativas e esforços, poucos artistas conseguiram notoriedade para abalar o sistema, para minimizar a distinção entre arte e vida ou, sendo mais explícito, entre arte e cotidiano. A notoriedade alcançada por Marcel Duchamp com a "Fonte", - urinol de porcelana branco, masculino, com a inscrição "R. Mutt" -, recusada para a exposição da Sociedade de Artistas Independentes de Nova York (1917), foi o golpe que ajudou a arte a descer do seu pedestal. A irreverência, ambivalência e rebeldia de Duchamp em relação aos princípios do sistema de arte da modernidade, refletiam sua profunda consciência do poder da arte como instituição social. Embora o trabalho-proposta de Duchamp seja da segunda década do século $X X$, é importante ressaltar que sua influência fez-se mais intensa a partir dos anos 50 .

Nos anos 60, uma grande variedade de movimentos - arte pop, arte conceitual, performance, instalações, arte ambiental, etc. - intensificaram abertamente a resistência às polaridades do sistema das belas artes buscando manter e até mesmo aprofundar a relação arte e vida. Artistas pop como Andy Warhol, continuaram fazendo paródias sobre a "sacrossanta aura do artista e da obra de arte e os artistas conceituais freqüentemente produziam peças que dificilmente podiam ser consideras obras" (SHINER, 2004, p.397).

Mas apesar dessa diversidade de tentativas e esforços, apenas trinta ou quarenta anos atrás ainda havia críticos e teóricos influentes que defendiam a categoria arte como a maneira mais adequada para qualificar uma obra literária, pictórica ou 
musical. Paradoxalmente a essa resistência institucional, sabemos que a crise desta noção de arte gerou dois pontos de convergência: de um lado, os artistas passaram a usar uma variada gama de materiais conseguindo que as instituições artísticas os aceitasse como arte; de outro, as próprias instituições artísticas passaram a usar e tirar proveito da polaridade arte versus artesanato, adquirindo e preservando esses diversos tipos de trabalho.

Embora possa parecer estranho, por diversas razões e em diferentes medidas, o etos das belas artes ainda está presente na filosofia educacional e nas práticas artísticas de escolas, institutos e departamentos de arte em instituições universitárias do nosso país. Por inércia ou por força de tradição, estas instituições, principalmente aquelas envolvidas com formação profissional, ainda tentam neutralizar os desafios da contemporaneidade fazendo vistas grossas às mudanças decorrentes da perda do estatuto ontológico da arte.

Todavia, aos poucos, pelas pressões do mercado de trabaIho, por questões econômicas ou, ainda, talvez, pela veemência da crítica social, as instituições começam a ceder e a ensaiar, mesmo que de maneira tímida, algumas mudanças. Tais mudanças partem de exigências sociais que provocam as instituições a esboçar algum tipo de resistência ou reação a novas abordagens, campos de investigação e saberes emergentes ainda não regulados pelo ofício profissional ou pelo "método" e, portanto, ainda não institucionalizados. Nessa arena de idéias, onde podemos inserir debates, publicações, eventos científicos e propostas curriculares, não é difícil observar que o conflito mais recente e ainda em curso tem sido motivado pela entrada em cena da cultura visual.

\section{Estreitando Focos}

A questão predominante sobre arte e imagem na literatura recente da cultura visual e da história da arte está relacionada à interpretação e a retórica (MITCHELL, 2005). Temos a preocupação de saber o quê e como as imagens significam enquanto 
signos e símbolos, qual o segredo da sua vitalidade e que "tipo de poder elas têm para afetar as emoções e o comportamento humano" (MITCHELL, 2005, p. 28). Não se trata simplesmente de fugir ou abandonar as questões referentes à interpretação e a retórica, como alerta Mitchell, mas de compreender as mudanças fundamentais que estão ocorrendo na história da arte, mudanças associadas ao que Mitchell cunhou como a "virada pictórica" e que têm implicações para ambas, cultura popular e cultura da elite.

Estas mudanças e, em conseqüência, atitudes, não estão circunscritas às obras de arte ou às imagens que possam ter um significado afetivo para as pessoas. Melhor do que qualquer um de nós, executivos de empresas de publicidade sabem muito bem que imagens "têm pernas", ou seja, têm "uma surpreendente capacidade para criar novos direcionamentos e viradas surpreendentes" (...) como se "tivessem inteligência e propósitos próprios"(Ibid., p. 3).

Freedman (2006) expõe, de maneira simples e clara, relações e sincretismos entre arte e imagem, novos direcionamentos e viradas surpreendentes aos quais Mitchell também se refere. Ela explica que,

Os pintores fazem performance, os performers fazem vídeos musicais, os artistas de vídeo reciclam trechos de filmes, os cineastas utilizam gráficos realizados em computador que depois são adaptados à publicidade, e os publicitários se apropriam de pinturas. (...) Vemos artes visuais na NASA e na Disneylândia, assim como no Louvre, e elas estão conectadas a diversas outras formas artísticas. Mediante conexões visuais, estas artes passam a fazer parte da cultura visual... (p. 42).

Este tipo de miscigenação artístico-imagética é, talvez, uma maneira mais contundente de descrever e caracterizar a cultura visual como campo emergente, transdisciplinar e transmetodológico que discute e trata arte e imagem "não apenas pelo seu valor estético, mas, principalmente, buscando compreender o papel da imagem na vida da cultura" (MARTINS, 2007, p. 26). Assim, fica evidente que a cultura visual não tem o objetivo de subestimar ou alijar da sua discussão as práticas artísticas das artes visuais porque elas "compõem a maior parte da cultura 
visual, que é tudo o que os humanos formam e sentem através da visão ou da visualização, e que dá forma ao modo como vivemos nossas vidas" (FREEDMAN, 2006, p. 25). O propósito da cultura visual é desenvolver um conhecimento mais profundo, rico e complexo colocando em perspectiva a "relevância que as representações visuais e as práticas culturais têm dado ao 'olhar' em termos das construções de sentido e das subjetividades no mundo contemporâneo" (HERNÁNDEZ, 2007, p. 27). Além disso, a cultura visual reconhece a importância não apenas da compreensão, mas também, da interpretação crítica.

A cultura visual desafia os limites do sistema das belas artes e suas instituições ao estudar o caráter cambiante dos objetos artísticos analisando-os como artefatos sociais; ao deslocar o foco das categorias artísticas tradicionais e disciplinas acadêmicas no estudo dos objetos, trabalhando deslocamentos da história e relações "intertextuais ou intervisuais, com possibilidade de múltiplas associações visuais e intelectuais" (GUASCH, 2005, p. 10); ao explorar conexões e contrastes entre as diversas formas de arte popular e das belas artes; ao incluir e discutir o impacto das imagens de cinema, de publicidade, de jogos de computador e histórias em quadrinho sobre adolescentes, jovens e adultos; ao ampliar limites culturais e educativos que abrangem outros seguimentos e grupos culturais, suas imagens e artefatos; ao enfatizar, deliberadamente, a relação arte e vida, ou seja, arte e imagem como parte do cotidiano, como parte de uma convivência diária com nossa diversidade e complexidade.

O conflito gerado pela entrada em cena da cultura visual põe um foco na visualidade, ponto em que história da arte e cultura visual se chocam. Visualidade é a visão socializada (WALKER e CHAPLIN, 2002). De acordo com Mitchell (2002), o que está em jogo é a "idéia da visão como uma prática social, como algo construído socialmente ou localizado culturalmente, ao mesmo tempo em que libera as práticas do ver de todo ato mimético, as eleva graças à interpretação" (Apud GUASCH, p. 11). A importância que Mitchell dá à interpretação reverbera em Jenks que corrobora com a posição de Bryson ao afirmar que "em relação à história da arte é crucial que a visão se as- 
socie mais com a interpretação que com a mera percepção" (Apud GUASCH, p. 1). Ao detalhar os argumentos apresentados por Bryson, Holly e Moxey (1994) em favor de uma história das imagens em lugar de uma história da arte, Guasch (2003) destaca duas questões:

Por um lado, primar o "significado cultural" da obra para além do seu valor "artístico" (o qual supõe reivindicar trabalhos que tradicionalmente haviam sido excluídos do cânone das "grandes obras de arte" como as imagens fílmicas ou as televisivas) e segundo, explicar as "obras canônicas" segundo vias distintas a seus inerentes valores estéticos, mas sem eliminá-los. O importante já não é buscar o valor estético da "arte erudita" mas examinar o papel da imagem "na vida da cultura" ou, dito com outras palavras, considerar que o valor de uma obra procede (não apenas) de suas características intrínsecas e imanentes, mas da apreciação do seu significado (e aqui é tão importante uma imagem televisiva como uma obra de arte), tanto dentro do horizonte cultural da sua produção como da sua recepção (p. 11).

As questões destacadas por Guasch, - significado cultural e valor estético - estão no centro das discussões sobre a cultura visual, ou seja, a premissa de que a visão é uma 'construção cultural' e, portanto, é algo aprendido e cultivado através de práticas sociais e de práticas educacionais desenvolvidas nas instituições. Por esta razão, fora do campo da cultura visual, a visualidade é vista como um conceito perigoso, coisa ardilosa. Sem dúvida, é um conceito difícil de ser delimitado de maneira sistemática. Para conflitos como estes, gerados por diferentes posições teóricas e pontos de vista, a cultura visual não oferece soluções em curto prazo.

Como campo emergente de investigação, a cultura visual quer ajudar aos indivíduos e, principalmente, aos alunos, a desenvolver uma visão crítica em relação ao poder das imagens, auxiliando-os a criar e aguçar um sentido de responsabilidade diante das liberdades decorrentes desse poder. Essas responsabilidades têm claras implicações éticas que Freedman explica como

liberdade de informação em toda uma gama de formas de arte visual necessárias para a criação do conhecimento individual e gru- 
pal. As pessoas não apenas podem falar livremente; podem acessar livremente, apresentar e duplicar, manipular eletronicamente e televisionar mundialmente. As imagens e os objetos da cultura visual são vistos constantemente e são interpretados instantaneamente, formando um novo conhecimento e novas imagens sobre a identidade e o entorno (2006, p. 27).

Sem uma visão crítica e sem um sentido de responsabilidade, as pessoas podem ser manipuladas pela crescente diversidade de imagens - de arte, publicidade, ficção e informação - que, de modo aparentemente inofensivo, invadem e acossam nosso cotidiano. A idéia de que as imagens têm vida cultural e exercem poder psicológico e social sobre os indivíduos é o bordão que ampara a cultura visual.

\section{Relevância da interpretação crítica}

Na perspectiva da cultura visual a interpretação se constitui como prática social que mobiliza a memória do ver, aciona e entrecruza sentidos da memória social construída pelo sujeito. Influenciadas pelo imaginário do lugar social as interpretações configuram processos de construção de sentidos e significados.

Concepção inclusiva, a cultura visual se apropria do conceito de interpretação dialógica instituindo e ambientando o princípio da heterogeneidade, núcleo central das reflexões pósestruturalistas. Ênfase dessas reflexões, o 'conceito de autor', as 'teorias sobre o sujeito' e a questão das 'múltiplas identidades' geram deslocamentos conceituais e interpretativos abrindo espaço para discussão sobre o modo como imagem e arte nos interpelam.

O conceito de autor se combina com o conceito de interpretação porque cada vez que se interpreta uma imagem está sendo construída uma forma de autoria. Tal deslocamento se deve, por um lado, ao distanciamento da noção metafísica de unidade, ou seja, da idéia de interpretação única, autorizada e reconhecida, e por outro, à multiplicidade de discursos e interpretações da arte e da imagem que geram mobilidades na posição de sujeito. A dispersão desse olhar centralizado e centralizador desencadeia um "processo dinâmico e transformador 
que vai interromper a imobilidade da interpretação e exposição baseadas [na relação] autor/objeto" (POLLOCK, 2004, p. 91). Esses deslocamentos - mudanças na noção de imagem e de arte, de autor e de sujeito em consonância com a compreensão de que ambas (imagem e arte) não contém uma verdade própria a ser encontrada, descrita ou decifrada - assinalam o advento da pós-modernidade.

O papel que arte e imagem desempenham na cultura e nas instituições educacionais não é refletir a realidade ou torná-la mais real, mas, articular e colocar em cena uma diversidade de sentidos e significados. Indivíduos de um mesmo grupo ou comunidade podem conviver com as mesmas imagens, mas cada um as vive e interpreta de maneira diferente, criando brechas e espaços de diversidade. As resistências à concepção inclusiva da cultura visual e ao princípio da diversidade de interpretações - dificuldades centrais na relação indivíduo arte/imagem - se manifestam através de grupos hegemônicos que aspiram impor e autorizar suas interpretações, seu nível de verdade, constrangendo professores, alunos e até mesmo pesquisadores a aceitá-las ou a lutar para libertá-las do habitus acadêmico.

As dificuldades que envolvem e, por vezes, emaranham essa relação se devem às circunstâncias do social, terreno incongruente atravessado por antagonismos, rivalidades e desconfiança explícitos e implícitos que emergem e se sedimentam a partir de diferentes ângulos, perspectivas e refinamentos. Implicações decorrentes dessas dificuldades, em especial da resistência ao principio da diversidade de interpretação, reforçam a compreensão de que "todo processo de identificação que nos outorgue uma identidade sócio-simbólica fixa está destinado ao fracasso. Porque o terreno do social (dialógico), não é apenas instável, mas ambivalente..." (ZAVALA, 1996, p. 70).

Como perspectiva excêntrica, o pensamento dialógico critica o pensamento "universalista" que incorpora uma visão 'internacional', globalizante. Problematiza e discute a vocação universalista que tem marcado o estudo/ensino de arte a partir de dois argumentos: 1) a desconstrução da arte como instituição, ação desenvolvida pelas vanguardas a partir dos anos 20 que tornou obsoleto o discurso e a crítica artística que tenha a 
pretensão de se definir como arte pura - 'belas artes' ou 'fine arts' - ou de se outorgar autoridade para definir a função da arte na sociedade; 2 ) a separação entre arte/produção simbólica e vida social.

O princípio que orienta esse posicionamento crítico tem como pressuposto o fato de que o mundo simbólico e suas formas são construções culturais e, portanto, mediados pela tradição. Assim, o conhecimento artístico só será crítico se confrontar a tradição e os cânones que mediam o mundo e as produções simbólicas. Ao tentar definir e preservar o papel/função da arte na sociedade as instituições acadêmicas renovam e reforçam a noção romântica de arte como submissão exclusiva à autoridade do cânone e da tradição.

Obras de arte, assim como imagens, são ideológicas e estão socialmente situadas. Os conflitos entre pensamento dialógico e pensamento universalista se intensificam quando grupos hegemônicos/dominantes e tradicionalistas aspiram transformar a interpretação da arte e das imagens em monólogo, em verdade, dotando-as de um caráter essencialista, valendo-se de juízos de valor, avaliações e classificações hierárquicas que além de excludentes, buscam estabelecer verdades perenes.

O conceito de dialogia - que pressupõe heterogeneidade, idéia de polifonia de vozes e que também se difundiu como intertextualidade - reconhece que no universo cultural as interações acontecem por meio de confluências, reciprocidades, simultaneidades e fronteiras. Fronteiras porosas, como espaços muitas vezes imaginários, espaços de trânsito e sem uma divisão a priori do que é bom e mal, culto ou popular.

Imagem e arte são artefatos que as interpretações constroem no processo de validarem a si mesmas, mas cujas implicações - interpretações mais ou menos adequadas - dependem do quê apresentam como resultado. A interpretação é um ato complexo que se realiza a partir da interpelação de várias práticas sócio-ideológicas e, por esta razão, está implicada em relações de concordância, resistência ou crítica a algo já valorado e de alguma maneira organizado, algo diante do qual se adota, de modo responsável, uma posição valorativa. Práticas sócioideológicas tais como o são obras de arte e imagens, operam 
dentro de regimes de verdade e não como certezas absolutas (FOUCAULT, 2006). Portanto, trabalhar com arte e com imagem pressupõe estar atento para essas condições, estar alerta, sobretudo, para as sugestões que Popkewitz oferece a pesquisadores e professores:

Entender que o olho não apenas vê, mas é socialmente disciplinado pela ordem, divisão e "criação" das possibilidades da organização do mundo e do sentido da identidade individual. Ao questionar como os olhos vêem, é possível questionar também como os sistemas de idéias "tornam" realidade o que é visto, pensado e sentido. Tais perguntas sobre a razão - ou seja, a construção social da razão (e as relações de poder embutidas nestas) - são os princípios pelos quais o agente "vê" e age para efetuar uma mudança (1999, p. 22).

Os sujeitos se constituem no espaço de diversidade, de diferença, nas frestas e interseções. Isto explicita que conhecimento, consciência e verdade não são realidades fixas e não se encontram em espaços delimitados. São fios de uma trama intercambiável que se faz, refaz e desfaz em múltiplas configurações e situações. Arte e imagem estão vestidas e revestidas por idéias e pontos de vista gerais e individuais, por valorações e sotaques alheios e muitas vezes estrangeiros. Esses elementos se entrelaçam, às vezes se fundem e freqüentemente se entrecruzam. Toda obra ou imagem é, de certa forma, uma opinião social e as formas artísticas e imagens estão encharcadas de valorações sociais.

A interpretação crítica se fundamenta em teorias contemporâneas que abrem espaço para pensar arte e imagem como parte e práxis de uma comunidade interpretativa, de uma cultura visual. Fundamenta-se também no princípio de que arte e imagens nos interpelam e nos formam, os significados mudam, mas ao mesmo tempo revelam uma dimensão do nosso pensamento coletivo e de nossas projeções, imaginárias ou sociais. Como concepção pedagógica, a interpretação crítica é uma abordagem transdisciplinar ou multidisciplinar que trata arte e imagem como narrativas socioculturais no contexto de diversas práticas sociais.

Trabalhar com interpretação crítica significa compreender 
que arte e imagem são ideológicas, e que o artístico, inclusive dentro da sua especificidade estética, faz parte de uma economia sociocultural que outorga às obras e às imagens uma dimensão de valor. É estar atento para deslocamentos privilegiando práticas dialógicas e heterogêneas. É, de certa forma, reconhecer que são muitas as visões e versões de cultura e que elas têm grande alcance porque ampliam as possibilidades de relação e diálogo de alunos e professores com a arte, com a imagem e com a cultura.

Adicionalmente, trabalhar com interpretação crítica implica, ainda, reconhecer que as interpretações estão sutilmente enredadas nas percepções e subjetividades de intérpretes, colocando sob suspeita a posição e a voz do autor - entendido sob uma concepção romântica - como "centro autorizado e autoritrio da compreenso" (ZAVALA, 1996, p. 18). Esse deslocamento do conceito de autor, conforme já comentado anteriormente, abre perspectivas para abordar a relação imagem/ obra-intérprete e nos alerta para o fato de que a compreensão depende da circunstância comunicativa. Cada imagem, cada obra, faz parte de uma rede, de um diálogo, e essa rede de informações, percepções e sentidos é ampla e incomensurável.

Essas relações, implicações e deslocamentos encontram, na clareza e simplicidade da reflexão de Richard Serra, argumentos que utilizo para concluir esta discussão:

O que quero é que minha obra não seja percebida apenas como mais uma produção estética. Se ela se converter em um lugar de referência para gente com idéias diversas e minha escultura for a experiência que lhes permita encontrar-se, será estupendo. Gostaria que esta instalação fosse um espaço público, aberto, onde qualquer pessoa pudesse vir, sobretudo os jovens. Mas, a menos que a obra seja inovadora, nada mudará. Assim ela deverá ser, formalmente inovadora, para que transforme as percepções, as emoções e a experiência (Conversação com Hal Foster, outubro/ novembro de 2004).

Os significados e sua constituição não se separam do contexto em que são construídos e vividos e, na atualidade, tempo cronológico e tempo da experiência são conflitantes, competem por espaço e por afeto. Mas cabe a cada um de nós 
- pesquisadores, críticos, docentes - agenciar mudanças para enriquecer a nossa experiência e a dos alunos, compreendendo que não são os artefatos que definem arte, imagem e cultura visual, mas o modo como aproximamos, relacionamos, vemos e olhamos tais artefatos. O objeto de estudo da cultura visual não é especificamente a arte ou a cultura popular, mas a interpretação crítica da arte, da imagem, do visual.

\section{Referências Bibliográficas}

ADORNO, Theodor. Teoria Esttica. Lisboa: Martins Fontes, 1970.

BRYSON, N., HOLLY, M. A., MOXEY, K. Visual Culture - Images and Interpretations. London: University Press of New England, 1994.

POL DROIT, Roger. Soy un Artificiero - tercera entrevista. In: Entrevistas con Michel Foucault. Barcelona: Paidós, 2006.

FREEDMAN, Kerry. Ensear La Cultura Visual - Currículum, estética y la vida social del arte. Barcelona: Octaedro, 2006.

GUASCH, Ana María. "Una historia cultural de la posmodernidad y del colonialismo. Lo intercultural entre lo global y lo local. In: Artes: La Revista - Facultad de Artes de la Universidad de Antioquia, Colombia. No 9/ Volumen 5/ enero-junio, 2005, p. 3-14.

A. M. Los Estudios Visuales - Un Estado de la Cuestión. In: Estudios Visuales, 1. Murcia: CENDEAC, noviembre 2003, p. 8-16.

HERNÁNDEZ, Fernando. Catadores da Cultura Visual - proposta para uma nova narrativa educacional. Porto Alegre: Mediação, 2007.

KAPROW, A. Essays on the Blurring of Art and Life. Berkley: University of California Press, 1993.

MARTINS, Raimundo. A cultura visual e a construção social da arte, da imagem e das práticas do ver. In: OLIVEIRA de OLIVEIRA, Marilda (Org.). Arte, Educao e Cultura. Santa Maria: editoraufsm, 2007, p. 19-40.

MITCHELL, W. J. T. What do pictures want? - The Lives and Loves of Images. Chicago: University of Chicago Press, 2005.

POLLOCK, G. "La Cultura visual y sus descontentos: Unirse al Debate", Estudios Visuales, 2, diciembre 2004, p. 87-96.

POPKEWITZ, Thomaz. Introduction. Critical traditions, modernisms and 
the posts. In: POPKEWITZ, T. \& FENDLER, L. (Orgs.). Critical theories in education. Nova York: Routledge, p. 1-17, 1999.

SERRA, Richard. Conversação com Hal Foster, outubro/novembro de 2004. Disponível em www.guggenheim bilbao.es/caste/exposiciones/permanente/materia_tiempo/materia_tiempo.htm. Acesso em 23 de junho de 2006.

SHINER, Larry. La invencin del arte - Una historia cultural. Barcelona: Paidós, 2004.

SHUSTERMAN, Richard. Vivendo a Arte - O pensamento pragmatista e a estética popular. São Paulo: Editora 34, 1998.

TRAFÍ, Laura. La Interpretacin del arte moderno como produccin narrativa - Una investigación interdisciplinar desde la historia crítica del arte y la educación artística. Tese de doutorado apresentada ao Departamento de Desenho da Universidade de Barcelona, 2003.

WALKER, J. e CHAPLIN, S. Uma Introduccin a la Cultura Visual. Barcelona: Octaedro, 2002.

ZAVALA, Iris. Escuchar a Bajtin. Madrid: Montesinos, 1996.

\section{RAIMUNDO MARTINS}

é professor titular da Faculdade de Artes Visuais da Universidade Federal de Goiás. Doutor em Educação/Artes pela Southern Illinois University (EUA), fez pós-doutoramento no Instituto de Educação da Universidade de Londres (1992) e na Unidade de Arte Educação do Departamento de Desenho da Faculdade de Belas Artes da Universidade de Barcelona, Espanha (2005/2006). É docente do Programa de Pós-Graduação em Cultura Visual. 